\title{
Effectiveness of a mobile phone application to increase access to sexual and reproductive health information, goods, and services among university students in Uganda: a randomized controlled trial
}

Elly Nuwamanya ${ }^{1,2^{*}}$, Robinah Nalwanga', Afra Nuwasiima', Janet U. Babigumira', Francis T. Asiimwe ${ }^{1}$, Joseph B. Babigumira ${ }^{3}$ and Vitalis P. Ngambouk ${ }^{2}$

\begin{abstract}
Background: University students are one of the most vulnerable groups to sexual reproductive health [SRH] threats like sexually transmitted infections [STIS], unwanted pregnancies, and unsafe abortions and often have limited access to SRH information, goods, and services. This study assessed the effectiveness of using a mobile phone application (APP) to increase access to SRH information, goods, and services among university students in Uganda.

Methods: Using data from a double-blinded randomized controlled trial, participants were randomly assigned to both the intervention (APP) and control (standard of care) arms. We executed descriptive analyses for baseline demographic characteristics by intervention, difference in difference (DID), and quantile regression analyses for both primary and secondary outcomes.
\end{abstract}

Results: The median age of participants was 21 years of age, and the majority were female (over 60\%), unemployed (over 85\%) and Christian (90\%). Over 50\% were resident in off-campus hostels and in a relationship. Between baseline and end-line, there was a significant increase in SRH knowledge score (DID $=2, P<0.001$ ), contraceptive use (DID $=6.6 \%, P<0.001)$, HIV Voluntary testing and counselling (DID $=17.2 \%, P<0.001)$, STI diagnosis and treatment $(\mathrm{DID}=12.9 \%, P<0.001)$, and condom use at last sex $(\mathrm{DID}=4 \%, P=0.02)$ among students who used the APP. There was a significant 0.98 unit increase in knowledge score (adjusted coefficient $=0.98, P<0.001$ ), a significant 1.6-fold increase in odds of contraceptive use (adjusted coefficient $=1.6, P=0.04$ ), a significant 3.5-fold increase in HIV VCT (adjusted coefficient $=3.5, \mathrm{P}<0.001$ ), and a significant 2-fold increase in odds of STI testing and treatment (adjusted coefficient $=1.9, \mathrm{P}<0.001$ ) after adjusting for demographic characteristics among APP users compared to the control group.

(Continued on next page)

\footnotetext{
* Correspondence: nuwellie37@gmail.com

'GHE Consulting, P.O Box 27011, Kampala, Uganda

${ }^{2}$ Department of Community Medicine and Public Health, Sahlgrenska

Academy, University of Gothenburg, P. O Box 414, 40530, Gothenburg,

Sweden

Full list of author information is available at the end of the article
}

(c) The Author(s). 2020 Open Access This article is licensed under a Creative Commons Attribution 4.0 International License, which permits use, sharing, adaptation, distribution and reproduction in any medium or format, as long as you give appropriate credit to the original author(s) and the source, provide a link to the Creative Commons licence, and indicate if changes were made. The images or other third party material in this article are included in the article's Creative Commons licence, unless indicated otherwise in a credit line to the material. If material is not included in the article's Creative Commons licence and your intended use is not permitted by statutory regulation or exceeds the permitted use, you will need to obtain permission directly from the copyright holder. To view a copy of this licence, visit http://creativecommons.org/licenses/by/4.0/ The Creative Commons Public Domain Dedication waiver (http://creativecommons.org/publicdomain/zero/1.0/) applies to the data made available in this article, unless otherwise stated in a credit line to the data. 


\begin{abstract}
(Continued from previous page)
Conclusion: A mobile phone application increased sexual and reproductive health information (knowledge score), access to goods (contraceptives), and services (HIV voluntary testing and counseling and sexually transmitted infection diagnosis and management) among sexually active university students in Uganda. Further technical development, including the refinement of youth-friendly attributes, extending access to the app with other platforms besides android which was pilot tested, as well as further research into potential economic impact and paths to sustainability, is needed before the app is deployed to the general youth population in Uganda and other low-income settings.
\end{abstract}

Trial registration: MUREC1/7 No. 07/05-18. Registered on June 29, 2018.

Keywords: Mobile phone application, Mobile health, Sexual and reproductive health, University, Students

\section{Background}

Many of the low-income countries of sub-Saharan Africa have predominantly young populations. Uganda is one such country with $78 \%$ of the general population below 30 years of age and adolescents aged 15-19 years, accounting for a quarter of the female population [1]. Given this age distribution, youth-friendly health services in Uganda and other low-income countries are a current and ongoing public policy imperative. One critical aspect of youth-friendly health services is in the area of sexual and reproductive health (SRH): young, often unmarried people are often excluded from SRH services (and research reporting) despite being sexually active [2]. This means that access to SRH information, goods, and services is a right that remains unrealized by the youth due to myriad factors, including economic hardship, social stigma, and community norms [3]. Consequently, youth access to SRH information, goods, and services is poor, and is reflected by high rates of teen pregnancy and pregnancy-related health problems, high unmet need for contraception, and low access to modern contraception $[4,5]$.

Nearly all low-income sub-Saharan African countries have also undergone a rapid increase in mobile and broadband internet coverage; the region is projected to have 1 billion sim connections and 500 million broadband connections by 2020 [6]. Additionally, there is an increasing penetration of technology hubs and internet developers, and an emerging tech-driven economy driven by young entrepreneurs [6]. In Uganda, there are 18 million unique mobile subscribers, well over half of the population has access to a mobile phone, network coverage is high (67\%), and there have been significant increases in 4G and mobile internet connections [7].

The confluence of SRH needs for a predominantly young population and high and increasing access to mobile internet presents a unique opportunity for the development of youthfriendly, innovative digital health intervention (DHIs), particularly interventions in mobile health (mHealth). A review of mHealth projects in Uganda identified over 20 applications, including use for health worker and patient training, healthcare delivery, treatment and patient management support, and health facility improvement [8]. These interventions tended to use predominantly voice and text messaging or apply devices, such as tablet computers, directly at the point of use or service [8].

One area of potential growth in mHealth is in the use of mobile phone apps (MPAs) to increase access to health services in general and SRH information, goods, and services, in particular. DHIs, particularly mHealth, are associated with key youth-friendly attributes, including confidentiality, convenience, and entertainment/information value. The leap from text messaging-based mHealth to internet-based MPAs maintains the confidentiality and convenience attributes and magnifies the information and entertainment value of mHealth interventions. It also allows the development of multiple platforms and connections that expand their utility from information-only use to use for connecting to goods and services. This enables complex, multifaceted interventions with multiple potential avenues of impact and a wide variety of client or consumer choice. Additionally, entertainment value and appeal portend the ability to advertise, a key determinant of market success and potential sustainability at scale of a commercial MPA.

As part of a broader project conducted over an 18month period, we developed and pilot-tested a MPA to increase access to SRH information, goods, and services in a population of university students in Kampala's capital, Uganda [9]. A detailed description of the development of the MPA has been described elsewhere (Development of a mobile phone application for access to sexual and reproductive health information, goods, and services in a low-income setting, Forthcoming). After MPA-development and as part of the impact evaluation, we conducted a study of acceptability and utilization of the MPA in which we assessed the proportion of eligible participants that accepted the MPA by downloading it and utilization as the proportion of eligible participants that used the app to access SRH information, goods and services in a six-month follow-up period (Acceptability and utilization of a mobile phone 
application to increase access to sexual and reproductive health information, goods, and services by university students in Uganda, Forthcoming). Acceptability was high at 84 , and $82 \%$ of participants that downloaded the app used it to access SRH information, goods, and services over a six-month period (Acceptability and utilization of a mobile phone application to increase access to sexual and reproductive health information, goods, and services by university students in Uganda, Forthcoming).

Given satisfactory acceptability and utilization estimates, we hypothesized that access to the MPA would lead to an increase in SRH knowledge and lead to an increase in access to SRH goods and services among university students.

\section{Methods}

\section{Study design}

The study was a randomized controlled trial in which access to SRH information, goods, and services using a MPA (MPA-SRH) was compared to the standard of care of access to SRH information, goods, and services (SOC$\mathrm{SRH})$. A protocol of the trial, which was a part of a broader app development and impact evaluation project, has been published previously [9]. The trial was approved by the Mbarara University of Science and Technology Ethical Review Committee and the Uganda National Council of Science and Technology and was registered at MUREC1/7 No. 07/05-18 on 29th June 2018.

\section{Participants}

The trial included students of Kyambogo University (KYU), the second-largest university in Uganda, which is situated in the capital city, Kampala. Eligibility criteria for inclusion into the trial were: (1) age 18 to 30 years, (2) self-reported sexual activity in the last six months, (3) more than 12 months to graduation, (4) access to an internet-enabled Android smartphone, and (5) informed consent. Trial participants were recruited in KYU halls of residence and KYU-affiliated hostels. Data were collected by in-person interviews in students' rooms.

\section{Intervention}

In the intervention group, trial participants were granted access to a MPA to enable their access to SRH information, goods, and services over a period of six months. Details of the development and features of the app are described elsewhere (Development of a mobile phone application for access to sexual and reproductive health information, goods, and services in a low-income setting, Forthcoming). Briefly, the MPA was developed in partnership with Gershom Technologies Ltd. using the Android operating system and archived on the Google Play store. The MPA was designed to link the different goods and services providers: healthcare facilities which provided SRH goods and services; Beyonic Uganda (https://beyonic.com/), a payments company which managed payments and co-payments; SafeBoda (https:// safeboda.com/ug/), a transport company which managed the transportation of ordered goods and app users to receive services; and GHE Consulting (https://www.gheuganda.com/) for coordination, management, and oversight.

The MPA included the following features: (1) sign-up and sign-in; (2) a user module for ordering SRH goods (sanitary pads, male condoms, contraceptives, pregnancy tests, and pain killers) and services (HIV voluntary testing and counseling (VTC), STI diagnosis and treatment (D\&T), family planning counseling, and general SRH consultation); (3) an SRH information module (menstrual period tracker, frequently-asked questions (FAQs), SRH tips, and a live chat); (4) a payments module to enable provider payments by GHE Consulting, copays by clients, and payments for transportation; (5) a delivery module to enable clients to track shipments, set up pickups for infacility visits, and set up pick up points for products; and (6) a security module for authentication and password protection. Embedded in the MPA was an advertising interface to test potential sustainability at the scale of inMPA advertising. While the study provided a major subsidy for SRH goods and services as well as transportation, there was a modest co-pay that was paid by app users through a link between mobile money and the Beyonic payment system. The co-pay was designed to test the utility of client payments in potential future iterations of the MPA after the pilot period.

\section{Procedures}

Intervention group participants received a text message with a link to download the MPA, including directions on the set up of a MPA account and instructions on the use of the MPA. Upon download of the MPA, participants could gain access to SRH information through the four in-app portals. Participants could order SRH goods and have them delivered to their rooms or to a designated spot for pick up. Participants could also connect with health service providers to book SRH services and connect with transport providers to organize transportation to and from healthcare facilities. Participants in the SOC-SRH group received no intervention, i.e., accessed SRH information, goods, and services as they did before the onset of the trial.

\section{Outcomes}

There were four primary outcomes in the trial all reflecting changes from baseline to end-line (end of six months follow-up period): SRH knowledge score (SRH information), use of contraceptives (SRH goods), use of HIV VTC (SRH services), and use of STI D\&T (SRH services). There 
were two secondary outcomes in the trial, both reflecting changes from baseline to end-line: use of condoms and use of alcohol during the last sexual encounter (both behavioral and attributable to SRH information).

\section{Sample size}

The sample size was calculated to detect a change between baseline and end-line in use of modern contraceptive goods. The prevalence of modern contraceptive use among sexually active youth aged 18 to 30 years at the time of study planning was $30.2 \%$. Using the formula for the use of the Z-test for two sample proportions in studies with behavioral components, we calculated a sample size of 435 participants per group in order to obtain $90 \%$ power to detect a $15 \%$ change in modern contraception use in this population at a two-sided significance level of $5 \%$. The sample size calculation assumed no design effect $(\mathrm{d}=1)$ and was adjusted for a $10 \%$ non-response rate to obtain a minimum sample size of 479 per group (a total of 958 participants).

\section{Randomization and masking}

After recruitment and informed consent, participants were informed that there was a 50-50 chance that they would be randomly assigned to gain access to the MPA (MPA-SRH) or be a part of the control group (SOCSRH). The participants' telephone numbers and unique study identification numbers were given to the app developer, who was responsible for randomization. Participants were randomized 1:1 to MPA-SRH and SOC-SRH using computer-generated random numbers. The research team, including providers at health facilities, transport providers, and payment technicians, and participants were blind to the intervention group, but the app developer was not.

\section{Statistical analysis}

Data were double-entered and cross-validated, and all analyses were conducted in Stata version 16 (College Station TX, USA). We compared outcomes between participants randomly assigned to MPA-SRH versus SOC$\mathrm{SRH}$, ignoring potential changes in access to SRH information, goods, and services in the SOC-SRH group that may have been triggered by the use of the app by participants in the MPA-SRH group.

SRH knowledge scores were summed from correct responses from 17 different attributes and ranged from 0 to 17 (each question was awarded 1 point). Contraceptive use, HIV VTC, STI D\&T, condom use during last sexual encounter, and alcohol use during the last sexual encounter were binary variables. We estimated the difference in changes from baseline to end-line (with 95\% confidence intervals (CIs) and p-values) using differences-indifferences. We used the Wilcoxon rank-sum test for the knowledge score and the Z-test for proportions.

Using quantile regression (knowledge score) and a logit link function (access to modern contraceptive use, HIV voluntary counseling and testing, and STI testing and treatment), we estimated a mean differences-indifferences effect, adjusting for demographic characteristics. Models were estimated using maximum likelihood.

\section{Results}

We enrolled participants from Oct 23rd, 2018, to 13th November 2018, and the last participant completed the six-month follow-up period on 25th May 2019. We

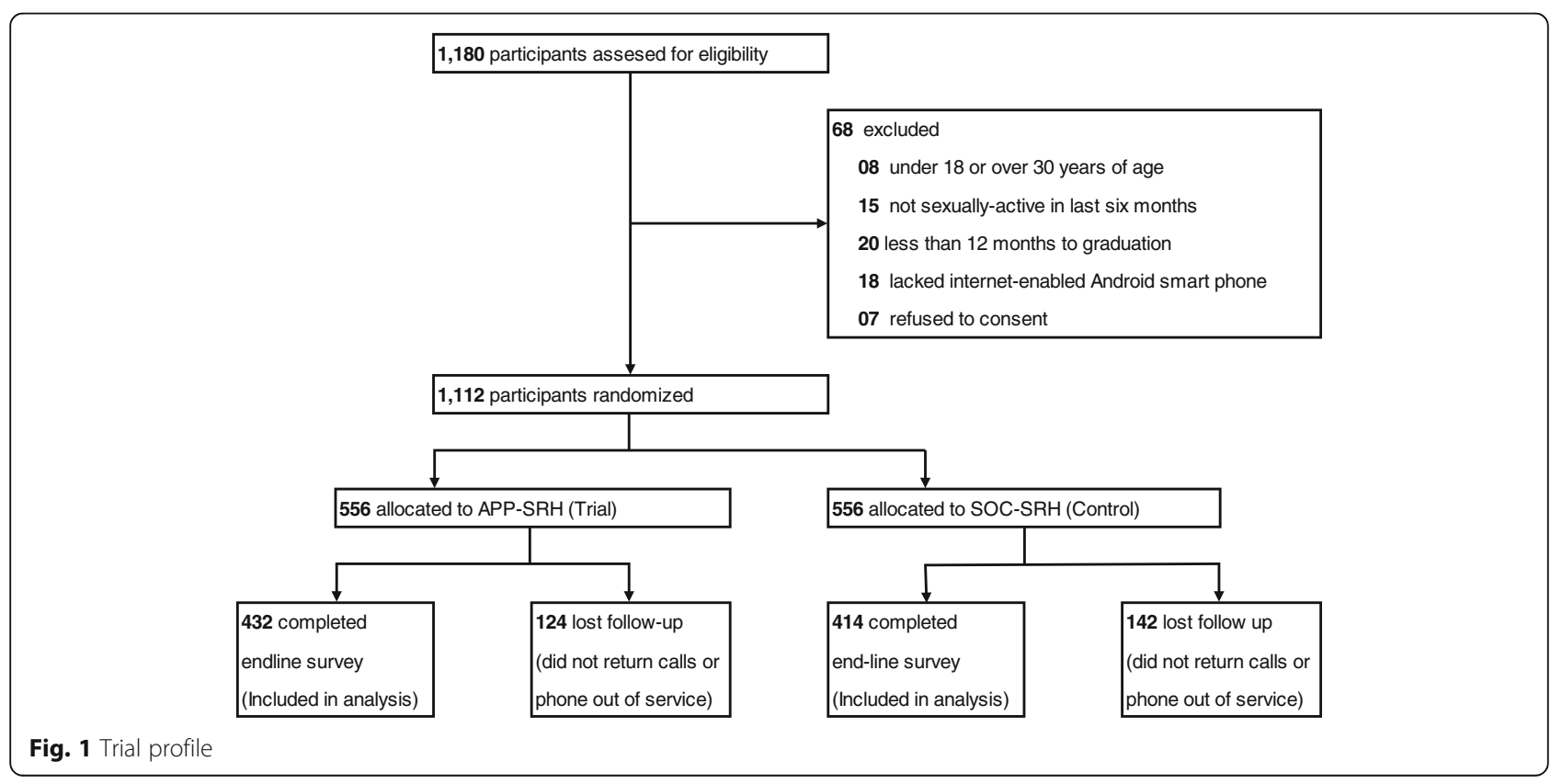


enrolled (and assessed for eligibility) 1180 students and randomized 1112 students, 556 to the MPA-SRH (trial arm), and 556 to the SOC-SRH (control arm). Of the participants randomized, 846 (76.1\%) completed the end-line survey, $432(76.1 \%)$ in the APP-SRH arm, and 414 (74.5\%) in the APP-SOC arm, constituting the sample for the analysis (Fig. 1).
The participants were predominantly women, resident in off-campus hostels, from urban hometowns, in relationships, in their first or second years of study, unemployed, and Christian. The loss to follow-up was predominantly due to participants not answering and returning calls or out-of-service telephone numbers. The baseline characteristics of the study participants are shown in Table 1. The

Table 1 Baseline characteristics of study participants by intervention

\begin{tabular}{|c|c|c|c|}
\hline Characteristic & APP-SRH & SOC-SRH & All \\
\hline & $(n=556)$ & $(n=556)$ & $(n=1112)$ \\
\hline Age at entry, years & $21(2[10,11] ;)$ & $21(2[10,11] ;)$ & $21(2[10,11] ;)$ \\
\hline \multicolumn{4}{|l|}{ Sex } \\
\hline Male & $214(38.5)$ & $193(34.7)$ & $407(36.0)$ \\
\hline Female & $342(61.5)$ & $363(65.3)$ & $705(63.4)$ \\
\hline \multicolumn{4}{|l|}{ Residence } \\
\hline Campus hall & $137(24.6)$ & $133(23.9)$ & $207(24.3)$ \\
\hline Off-campus hostel & $301(54.1)$ & $317(57.0)$ & $618(55.6)$ \\
\hline Rental home & $104(18.7)$ & $86(15.5)$ & $190(17.1)$ \\
\hline Own home & $02(0.36)$ & $03(0.5)$ & $05(0.45)$ \\
\hline Parent/ Guardian home & $12(2.16)$ & $17(3.1)$ & $29(2.6)$ \\
\hline \multicolumn{4}{|l|}{ Hometown } \\
\hline Urban & $231(41.6)$ & $228(41.0)$ & $459(41.3)$ \\
\hline Peri-urban & $184(33.1)$ & $189(33.9)$ & $373(33.5)$ \\
\hline Rural & $141(25.4)$ & $139(25.0)$ & $280(25.2)$ \\
\hline \multicolumn{4}{|l|}{ Marital status } \\
\hline Relationship & $298(53.6)$ & $299(53.8)$ & $594(53.7)$ \\
\hline Single & $239(42.9)$ & $241(43.4)$ & $480(43.2)$ \\
\hline Cohabiting & $13(2.3)$ & $08(1.4)$ & $21(1.89)$ \\
\hline Married & $04(0.7)$ & $08(1.4)$ & $12(1.08)$ \\
\hline Divorced & $01(0.2)$ & $00(0.0)$ & $01(0.09)$ \\
\hline Widowed & $01(0.2)$ & $00(0.0)$ & $01(0.09)$ \\
\hline \multicolumn{4}{|l|}{ Year of study } \\
\hline First & $174(31.3)$ & $195(35.1)$ & 369 (33.2) \\
\hline Second & 209 (37.6) & $201(36.2)$ & $410(36.9)$ \\
\hline Third & $147(26.4)$ & $134(24.1)$ & $281(25.3)$ \\
\hline Fourth & $24(4.3)$ & $26(4.68)$ & $50(4.5)$ \\
\hline Fifth & $02(0.36)$ & $00(0.0)$ & $02(0.18)$ \\
\hline \multicolumn{4}{|l|}{ Employment } \\
\hline Unemployed & $475(85.4)$ & $495(89.0)$ & $970(87.2)$ \\
\hline Employed & $46(8.3)$ & $37(6.7)$ & $83(7.5)$ \\
\hline Volunteer & $01(0.18)$ & $02(0.4)$ & $03(0.27)$ \\
\hline Self-employed & $34(6.1)$ & $22(3.9)$ & $56(5.04)$ \\
\hline \multicolumn{4}{|l|}{ Religion } \\
\hline Christian & $500(89.9)$ & $486(87.4)$ & $986(88.7)$ \\
\hline Muslim & $43(7.7)$ & $45(8.1)$ & $88(7.9)$ \\
\hline Others & $13(2.3)$ & $25(4.5)$ & $38(3.4)$ \\
\hline
\end{tabular}


Table 2 Differences-in-differences analysis of primary and secondary outcomes

\begin{tabular}{|c|c|c|c|c|c|c|c|}
\hline & \multicolumn{3}{|l|}{ MPA-SRH } & \multicolumn{3}{|l|}{ SOC-SRH } & \multirow{2}{*}{$\begin{array}{l}\text { DID [P-value: } 95 \% \\
\mathrm{CI}]\end{array}$} \\
\hline & Baseline & End-line & Difference & Baseline & End-line & Difference & \\
\hline Knowledge score & $13(11-15)$ & $16(15-16)$ & $03(z=-20.64,0.02)$ & $13(11-14)$ & $14(13-15)$ & $01(z=-9.01,0.01)$ & $02(z=4.69,0.00)^{*}$ \\
\hline Contraceptive use & $69.1 \%$ & $82.2 \%$ & 13.1\%[0.00: 7.8-18.4] & $73.7 \%$ & $80.2 \%$ & 06.5\% [0.02:1.2-11.8] & $06.6 \%[0.00: 3.0-10.4]^{*}$ \\
\hline HIV VTC & $68.0 \%$ & $90.5 \%$ & $22.5 \%[0.00: 17.8-27.3]$ & $64.2 \%$ & $69.6 \%$ & $05.4 \%$ [0.09: $-0.6-11.3]$ & $17.2 \%[0.00: 13.0-21.4]^{]}$ \\
\hline$S T I D \& T$ & $52.3 \%$ & $82.2 \%$ & $29.8 \%[0.00: 24.3-35.3]$ & $52.3 \%$ & $69.3 \%$ & $17.0 \%[0.00: 10.9-23.1]$ & $12.9 \%[0.00: 7.6-18.1]^{*}$ \\
\hline Condom use & $66.2 \%$ & $76.8 \%$ & $10.4 \%$ [0.00: 5.1-16.3] & $66.6 \%$ & $73.0 \%$ & 06.4\% [0.03: 0.6-12.2] & $04.0 \%[0.02: 0.8-7.8]^{*}$ \\
\hline Alcohol use & $7.6 \%$ & $10.9 \%$ & $03.3 \%[0.07:-0.3-7.0]$ & $04.0 \%$ & $07.5 \%$ & 03.5\%[0.02: 0.5-6.5] & $-00.2 \%[0.86:-0.2-2.1]$ \\
\hline
\end{tabular}

*implies statistical significance at less than $5 \%$

median age of participants was 21 years of age, and the majority were female (over 60\%), unemployed (over 85\%) and Christian (90\%). Over 50\% were resident in offcampus hostels and in a relationship.

Data are median (IQR; [range]), or $\mathrm{n}(\%)$. APP $=$ mobile phone application. $\mathrm{SRH}=$ sexual and reproductive health. $\mathrm{SOC}=$ standard of care.

Between baseline and end-line, there was a significant increase in SRH knowledge score, contraceptive use, HIV VTC, STI D \&T, and condom use at last sex among APP users compared to the SOC-SRH (Table 2). There was a modest non-significant reduction in alcohol use at last sexual encounter among APP users compared to the SOC-SRH (Table 2). There was a significant 0.98 unit increase in knowledge score, a significant 1.6-fold increase in odds of contraceptive use, a significant 3.5-fold increase in HIV VCT, and a significant 2-fold increase in odds of STI testing and treatment after adjusting for demographic characteristics among APP users compared to the SOC-SRH (Table 3).

\section{Discussion}

We assessed the effectiveness of a MPA to increase access to SRH information (measured as an increase in knowledge score and use of condoms and alcohol during the last sexual encounter), goods (measured as the proportion of participants using modern contraception), and services (a proportion that used HIV VCT and STI D\&T) in a population of university students in Uganda. The MPA had a statistically significant benefit in increased SRH knowledge and increased access to SRH goods and services. MPAs are increasingly used in low- and middleincome countries for a wide range of applications, although applications in this setting are far exceeded by applications in high-income settings [12]. In sub-Saharan Africa and in the area of SRH, apps have been deployed to the public to support family planning [13] and to healthcare workers for improving provider quality of maternal and neonatal care [10, 14-19]. To our knowledge, this is the first report of an app deployed to members of the public to increase access to SRH information, goods, and services in the low-income setting.

Internet-enabled mobile phones and MPAs, including social media platforms, are popular among the youth around the world. In some settings, access to MPAs is associated with negative behavioral outcomes: as an example, a study in South Africa found increased odds of multiple sexual partners in the last year and higher prevalence of hazardous alcohol use with access to social media and messaging apps [20]. The configuration of MPAs to deliver health improving information is a potential avenue to counter the potential negative impact of other more generic apps such as social media and messaging apps on youth behavior while increasing

Table 3 Regression analyses

\begin{tabular}{|c|c|c|c|c|c|c|c|c|}
\hline & \multicolumn{2}{|l|}{ Knowledge score } & \multicolumn{2}{|c|}{ Contraceptive use } & \multicolumn{2}{|l|}{ HIV VTC } & \multicolumn{2}{|c|}{ STI testing and treatment } \\
\hline & Unadj. & Adj. & Unadj. & Adj. & Unadj. & Adj. & Unadj. & Adj. \\
\hline Constant & $\begin{array}{l}13.00 \\
{[0.00(12.73,13.26)]^{*}}\end{array}$ & $\begin{array}{l}10.26 \\
{[0.00(7.63,12.69)]^{*}}\end{array}$ & $\begin{array}{l}2.81 \\
{[0.00(2.32,3.39)]^{*}}\end{array}$ & $\begin{array}{l}0.45 \\
{[0.41(0.06,3.11)]}\end{array}$ & $\begin{array}{l}1.79 \\
{[0.00(1.51,2.13)]^{*}}\end{array}$ & $\begin{array}{l}0.33 \\
{[0.25(0.52,2.15)]}\end{array}$ & $\begin{array}{l}1.10 \\
{[0.27(0.03,1.30)]}\end{array}$ & $\begin{array}{l}0.27 \\
{[0.15(0.46,1.58)]}\end{array}$ \\
\hline Intervention & $\begin{array}{l}0.00 \\
{[1.00(-0.38,0.38)]}\end{array}$ & $\begin{array}{l}0.35 \\
{[0.07(-0.03,0.734)]}\end{array}$ & $\begin{array}{l}0.81 \\
{[0.09(0.61,1.03)]}\end{array}$ & $\begin{array}{l}0.73 \\
{[0.02(0.56,0.96)]^{*}}\end{array}$ & $\begin{array}{l}1.18 \\
{[0.18(0.92,1.52)]}\end{array}$ & $\begin{array}{l}1.55 \\
{[0.27(0.90,1.49)]}\end{array}$ & $\begin{array}{l}1.00 \\
{[1.00(0.79,1.27)]}\end{array}$ & $\begin{array}{l}1.02 \\
{[0.86(0.80,1.3)]}\end{array}$ \\
\hline End-line & $\begin{array}{l}0.10 \\
[-0.59,1.14)]\end{array}$ & $\begin{array}{l}1.90 \\
{[0.00(1.42,2.37)]^{*}}\end{array}$ & $\begin{array}{l}1.44 \\
{[0.02(1.06,1.96)]^{*}}\end{array}$ & $\begin{array}{l}1.56 \\
{[0.01(1.1,2.22)]^{*}}\end{array}$ & $\begin{array}{l}1.27 \\
{[0.08(0.97,1.67)]}\end{array}$ & $\begin{array}{l}1.44 \\
{[0.03(1.05,1.98)]^{*}}\end{array}$ & $\begin{array}{l}2.16 \\
{[0.00(1.58,2.69)]^{*}}\end{array}$ & $\begin{array}{l}2.48 \\
{[0.00(1.74,3.26)]^{*}}\end{array}$ \\
\hline $\begin{array}{l}\text { Intervention * End- } \\
\text { line }\end{array}$ & $\begin{array}{l}2.00 \\
{[0.29(1.42,2.58)]}\end{array}$ & $\begin{array}{l}0.98 \\
{[0.00(0.29,1.46)]^{*}}\end{array}$ & $\begin{array}{l}1.43 \\
{[0.10(0.93,2.21)]}\end{array}$ & $\begin{array}{l}1.58 \\
{[0.04(1.02,2.46)]}\end{array}$ & $\begin{array}{l}3.53 \\
{[0.00(2.23,5.57)]^{*}}\end{array}$ & $\begin{array}{l}3.57 \\
{[0.00(2.24-5.68)]^{*}}\end{array}$ & $\begin{array}{l}2.04 \\
{[0.00(1.37,3.04)]^{*}}\end{array}$ & $\begin{array}{l}1.99 \\
{[0.00(1.26,2.86)]^{*}}\end{array}$ \\
\hline $\mathrm{N}$ & 1958 & 1958 & 1958 & 1954 & 1958 & 1946 & 1958 & 1954 \\
\hline Log-likelihood & - & - & -1072.59 & -1043.67 & -1101.17 & -1077.2 & -1227.27 & -1181.64 \\
\hline AIC & - & - & 2153.17 & 2147.33 & 2210.34 & 2212.41 & 2462.55 & 2423.27 \\
\hline
\end{tabular}

* implies statistical significance at less than 5\%: Coefficients and P-values and $95 \%$ confidence intervals in parenthesis 
access to health services such as SRH services. Our study demonstrated a significant increase in condom use during the last sexual encounter, suggesting a potential impact of a MPA on short-term behavioral change.

Research has established that the youth in low-income settings have significant SRH needs and face barriers to access to SRH goods and services, including physical access, legal and societal proscriptions, and societal barriers $[11,21]$. There is substantial evidence that increasing youth-friendly information and access to SRH information and services are effective in fulfilling needs and alleviating barriers [11]. In our study, the MPA led to increased SRH knowledge and increased use of contraception, HIV VCT, and STI D\&T, suggesting that the MPA was sufficiently youth-friendly to derive impact. Although there were some technical difficulties in the use of the MPA, these can be solved in future iterations of the MPA as plans are made for the transition to scale. And although our current focus was on a usable, deployable product, future prototypes will focus on refining youth-friendly attributes.

One weakness of the study was that the length of access to most components of the intervention (live chat and subsidies for goods, services, and information) were available for a short time (six months). As such, we are blind to the presence or absence of a sustained effect of increased knowledge or increase access to SRH goods and services on account of access to the MPA. Additionally, the trial was conducted among university students who are not generalizable to the general youth population in Uganda or other low-income countries. In fact, access to SRH information, goods, and services was high at baseline (13/17 knowledge score, over $70 \%$ access to contraception, $65 \%$ ever undergone $\mathrm{HIV} \mathrm{VCT}$, and $50 \%$ ever undergone STI diagnosis and treatment). This is compared to a general population contraceptive use prevalence of $29 \%$ among women of reproductive age [22] or $47 \%$ among unmarried women [1], and the prevalence of HIV testing among 15-19-year-olds of $44 \%$ in women and $53 \%$ in men [1]. University students are also different from the general population in their increased access to both smartphones and internet connections. Although the results of this study are not generalizable to the general youth population, we anticipate increasing access to smartphones and internet access $[6,23,24]$ and plan to explore the feasibility and effectiveness of SRH MPAs in the general population in future studies.

The demonstration of the effectiveness of the MPA to increase access to SRH information, goods, and services, along with lessons learned in the pilot implementation and impact evaluation is a necessary precursor to the further development of the MPA with the goal of developing a sustainable product that can be rolled out to the general public. Before this goal is realized, further studies of the cost-effectiveness of the MPA and its potential economic impact at scale are needed, as are studies on the perception of potential advertisers, key partners in a possible future product, on the potential of the MPA to drive revenue.

\section{Conclusion}

A mobile phone application increased sexual and reproductive health information (knowledge score), access to goods (contraceptives), and services (HIV voluntary testing and counseling and sexually transmitted infection diagnosis and management) among sexually active university students in Uganda. Further technical development, including the refinement of youth-friendly attributes, as well as further research into potential economic impact and paths to sustainability, is needed before the app is deployed to the general youth population in Uganda and other low-income settings. This will enable uniform access to the app by allowing users from other platforms other than the android platform, which was pilot tested.

\section{Abbreviations \\ APP: Mobile Phone Application; Cls: Confidence Intervals; D\&T: Diagnosis and Treatment; DHIs: Digital Health Interventions; FAQs: Frequently Asked Questions; IQR: Inter Quartile Range; KYU: Kyambogo University; mHealth: Mobile Health; MPAs: Mobile Phone Apps; SOC: Standard of Care; SRH: Sexual and reproductive health; STI: Sexually Transmitted Infections; VTC: Voluntary Testing and Counseling}

\section{Acknowledgements}

We want to thank all partner clinics, notably NIM medical Centre, Alpha medical Centre and Kyambogo Medical Centre. We would also like to thank the KYU administration and students for their cooperation during the study period. We immensely appreciate all other partners that contributed to the success of this study.

\section{Authors' contributions}

All authors conceived the study. EN wrote the first draft of the manuscript. All authors revised and approved the final version of this manuscript.

\section{Funding}

The study was funded by Grand Challenges Canada under grand number RST-POC-1808-17421. Grand Challenges Canada did not have any role in the preparation of the protocol, analysis of data, or decision to submit the manuscript for publication.

Availability of data and materials

All the data used and presented in this study are available upon request.

Ethics approval and consent to participate

The trial was approved by the Mbarara University of Science and Technology Ethical Review Committee and the Uganda National Council of Science and Technology and was registered at MUREC $1 / 7$ No. 07/05-18 on 29th June 2018. All participants consented before participating in the study.

Consent for publication

Not applicable.

Competing interests

The authors declare that they have no competing interests. 


\section{Author details}

${ }^{1}$ GHE Consulting, P.O Box 27011, Kampala, Uganda. ${ }^{2}$ Department of Community Medicine and Public Health, Sahlgrenska Academy, University of Gothenburg, P. O Box 414, 40530, Gothenburg, Sweden. ${ }^{3}$ Global Medicines Program, Department of Global Health, University of Washington, P.O Box 357630, Seattle, WA 98195, USA.

Received: 7 July 2020 Accepted: 21 October 2020

Published online: 31 October 2020

\section{References}

1. Uganda Bureau of Statistics (UBOS) and ICF. Uganda demographic and health survey 2016. Kampala, Uganda and Rockville, Maryland, USA: UBOS and ICF; 2018

2. Darroch JE, et al. Research gaps in adolescent sexual and reproductive health. New York: Guttmacher Institute; 2016. https://www.guttmacher.org/ report/research-gaps-in-sexual-and-reproductive-health.

3. Rijsdijk LE, Lie R, Bos AER, Leerlooijer JN, Kok G. Sexual and reproductive health and rights: implications for comprehensive sex education among young people in Uganda. Sex Educ. 2013;13:409-22.

4. Kassa GM, Arowojolu AO, Odukogbe AA, Yalew AW. Prevalence and determinants of adolescent pregnancy in Africa: a systematic review and meta-analysis. Reprod Health. 2018;15:195.

5. Adding It Up: Investing in Contraception and Maternal and Newborn Health for Adolescents in Uganda, 2018. Accessed on 22 Oct 2019 at https://www. guttmacher.org/fact-sheet/adding-it-up-contraception-mnh-adolescentsuganda.

6. The Mobile Economy. Sub-Saharan Africa 2017. Accessed on 16 Oct 2018 at https://www.gsmaintelligence.com/research/?file=7bf3592e6d750144e5 8d9dcfac6adfab\&download.

7. Calum Handforth and Matthew Wilson. Digital Identity Country Profile: Uganda. Accessed on 22 Oct 2019 at https://www.gsma.com/ mobilefordevelopment/wp-content/uploads/2019/02/Digital-IdentityCountry-Report-Uganda.pdf.

8. Kiberu VM, Mars M, Scott RE. Barriers and opportunities to implementation of sustainable e-health programmes in Uganda: a literature review. African J Primary Health Care Family Med. 2017:9:e1-e10.

9. Nuwamanya E, Nuwasiima A, Babigumira JU, Asiimwe FT, Lubinga SJ, Babigumira JB. Study protocol: using a mobile phone-based application to increase awareness and uptake of sexual and reproductive health services among the youth in Uganda. Reproductive Health. 2018;15:216.

10. Tsai AC, Tomlinson M, Dewing S, le Roux IM, Harwood JM, Chopra M, Rotheram-Borus MJ. Antenatal depression case finding by community health workers in South Africa: feasibility of a mobile phone application. Arch Womens Ment Health. 2014;17:423-31.

11. Chandra-Mouli V, McCarraher DR, Phillips SJ, Williamson NE, Hainsworth G. Contraception for adolescents in low and middle income countries: needs, barriers, and access. Reprod Health. 2014;11:1.

12. Abaza H, Marschollek M. mHealth Application Areas and Technology Combinations*. A comparison of literature from high and low/middle income countries. Methods Inf Med. 2017;56:e105-22.

13. Shelus V, Ashcroft N, Burgess S, Giuffrida M, Jennings V. Preventing pregnancy in Kenya through distribution and use of the CycleBeads Mobile application. Int Perspect Sex Reprod Health. 2017;43:131-41.

14. Thomsen CF, Barrie AMF, Boas IM, Lund S, Sorensen BL, Oljira FG, Tersbol BP. Health workers' experiences with the safe delivery app in west Wollega zone, Ethiopia: a qualitative study. Reprod Health. 2019;16:50.

15. Willcox M, Moorthy A, Mohan D, Romano K, Hutchful D, Mehl G, Labrique A LeFevre A. Mobile Technology for Community Health in Ghana: is maternal messaging and provider use of technology cost-effective in improving maternal and child health outcomes at scale? J Med Internet Res. 2019;21: e11268.

16. Shiferaw S, Workneh A, Yirgu R, Dinant GJ, Spigt M. Designing mHealth for maternity services in primary health facilities in a low-income setting lessons from a partially successful implementation. BMC Med Inform Decis Mak. 2018;18:96

17. Hackett K, Lafleur C, Nyella P, Ginsburg O, Lou W, Sellen D. Impact of smartphone-assisted prenatal home visits on women's use of facility delivery: results from a cluster-randomized trial in rural Tanzania. PLoS One. 2018;13:e0199400
18. Shiferaw S, Spigt M, Tekie M, Abdullah M, Fantahun M, Dinant GJ. The effects of a locally developed mHealth intervention on delivery and postnatal care utilization: a Prospective Controlled Evaluation among Health Centres in Ethiopia. PLoS One. 2016;11:e0158600.

19. McNabb M, Chukwu E, Ojo O, Shekhar N, Gill CJ, Salami H, Jega F. Assessment of the quality of antenatal care services provided by health workers using a mobile phone decision support application in northern Nigeria: a pre/post-intervention study. PLoS One. 2015;10:e0123940.

20. Kaufman ZA, Braunschweig EN, Feeney J, Dringus S, Weiss H, DelanyMoretlwe S, Ross DA. Sexual risk behavior, alcohol use, and social media use among secondary school students in informal settlements in Cape Town and Port Elizabeth, South Africa. AIDS Behav. 2014;18:1661-74.

21. Renzaho AM, Kamara JK, Georgeou N, Kamanga G. Sexual, reproductive health needs, and rights of young people in slum areas of Kampala, Uganda: A Cross Sectional Study. PLoS One. 2017;12:e0169721.

22. Ba DM, Ssentongo P, Agbese E, Kjerulff KH. Prevalence and predictors of contraceptive use among women of reproductive age in 17 sub-Saharan African countries: a large population-based study. Sexual \& Reproductive Healthcare. 2019;21:26-32.

23. Deloitte. Global mobile consumer trends, 2nd edition Mobile continues its global reach into all aspects of consumers' lives. Accessed at https://www2. deloitte.com/content/dam/Deloitte/us/Documents/technology-mediatelecommunications/us-global-mobile-consumer-survey-second-edition.pdf on 21 Sept 2019.

24. National Information Technology Survey 2017/18 Report Study conducted by: The Collaboration on International ICT Policy for East and Southern Africa (CIPESA). Accessd at https://www.nita.go.ug/sites/default/files/ publications/National\%201T\%20Survey\%20April\%2010th.pdf on 21 Sept 2019.

\section{Publisher's Note}

Springer Nature remains neutral with regard to jurisdictional claims in published maps and institutional affiliations.
Ready to submit your research? Choose BMC and benefit from:

- fast, convenient online submission

- thorough peer review by experienced researchers in your field

- rapid publication on acceptance

- support for research data, including large and complex data types

- gold Open Access which fosters wider collaboration and increased citations

- maximum visibility for your research: over $100 \mathrm{M}$ website views per year

At $\mathrm{BMC}$, research is always in progress.

Learn more biomedcentral.com/submission 